\title{
Everyday influence - democracy when health and social care are part of everyday life
}

\author{
Eric Asaba ${ }^{1,2,3}$ (D), Margarita Mondaca ${ }^{1}$ (D), Staffan Josephsson ${ }^{1}$ (D) and Karin Johansson ${ }^{1 *}$ (D) \\ ${ }^{1}$ Department of Neurobiology, Care Sciences, and Society (NVS), Division of Occupational Therapy, \\ Karolinska Institutet, Huddinge, Sweden, ${ }^{2}$ Unit for Research, Education, Development, and Innovation, \\ Stockholms Sjukhem Foundation, Stockholm, Sweden and ${ }^{3}$ Research Group in Occupational Therapy and \\ Occupational Science, Lund University, Lund, Sweden \\ ${ }^{*}$ Corresponding author. Email: Karin.e.johansson@ki.se
}

(Accepted 11 October 2021)

\begin{abstract}
This article contributes to ongoing discussions about frailty and vulnerability in critical gerontology by asserting that possibilities to engage and enact influence in everyday life situations is a crucial dimension of democracy in later life. We discuss how democracy in this sense can be threatened for older persons for whom health and social care services are needed, following from the labelling practices of frailty and the non-recognition of the social processes that set capabilities in motion. We utilise three examples grounded in research with older persons in their home environment in a Swedish context. The examples show how older people use creative, emotional, practical and social resources to integrate activities in a manner that address their needs and capabilities, and influence the situations in direction towards how and when to be engaged in everyday activities. Based on a discussion of the examples, we argue that health and social care services that provide and build social infrastructures need to recognise the potential concurrency of interdependency, vulnerability and agency within older persons' local everyday practices. This to address capabilities and enable concrete expression of democracy in everyday situations. Overall, we suggest that conceptual and methodological shifts in research, as well as policy and practice, are needed to bring democratic processes forward through the relational and situated aspects of resources, agency and influence.
\end{abstract}

Keywords: frailty; vulnerability; capability; health care; social care

\section{Introduction}

In this article, the authors aim to contribute to conceptual development as well as propose practice shifts needed to enhance influence and democracy for older people who face multiple challenges in everyday life. We build on ongoing discussions in critical gerontology through the use of concepts such as democracy, frailty and influence to unveil an inherent problem in values that imbue health and social 
services for older people. We propose that having possibilities to engage and enact influence in everyday life situations is a crucial dimension of democracy. We further discuss how democracy in this sense can be threatened for older persons for whom health and social care services are an integral part of everyday life, following from the labelling practices of frailty and the non-recognition of the social processes that set capabilities in motion.

\section{Influence in everyday life}

We will use democracy to position and conceptualise the importance of equal possibilities for all citizens to actually influence matters that shape their everyday life, as has been discussed by, for example, Amartya Sen (2010) and Martha Nussbaum (2011). This might include influence in decision-making on global, national or local political and organisational levels, but also includes influence in emerging everyday life situations encompassed by the social relations through which people negotiate power. As such, democracy is an expression of power that emerges in everyday practices, through interdependent actions on people's own terms (Mondaca, 2018). The conceptualisation of democracy applied in this article differs from the commonly applied conceptualisation and operationalisation of democracy as the articulation and execution of autonomy and rights, which focuses on juridical issues that promote individual citizens to execute their rights. While citizen rights can be seen as an ultimate condition for influence in everyday matters, this conceptualisation still tends to dismiss how democracy can be manifested in everyday life. In line with Nussbaum (2011), we argue that democracy is not only an issue of rights being recognised, but also about how capabilities are addressed and how concrete expressions of these rights are enabled in everyday situations.

A conceptualisation of democracy that includes influence on an everyday basis is important in situations where people, for different reasons, have difficulties utilising traditional instruments to articulate and enact their autonomy and rights. Research indicates that this is particularly relevant in the context of chronic conditions and old age, because in these situations people tend to identify their needs, preferences and expectations through everyday practices, rather than explicitly in terms of autonomous choices and rights (Eales and Keating, 2001; Heikkinen, 2004; Wray, 2004; Grenier, 2007; Larsson, 2009; Mondaca et al., 2019). This becomes particularly pertinent in situations where older persons need support from health and social care services to manage everyday life. Discussing such situations through the lens of democracy brings a shift in perspective from needs and passivity towards human rights and reciprocity in the context of old age and vulnerability.

\section{Defined as frail - a prerequisite for being eligible for support in everyday life}

While definitions of frailty vary, the overall aim with the increasing attention to the concept in medical and social gerontology and associated practices is to identify older people at risk for adverse health or social outcomes, and to target interventions to those individuals (Pickard, 2014; Tomkow, 2020). The increased interest in frailty conjugates with a shift from a general welfare system towards the provision 
of resources targeting only individuals and groups with the most needs. During the last decades in Sweden, and in other European contexts, this shift has been driven by the logics of cost-effectiveness inherent in neoliberalism (Grenier, 2007; Szebehely and Trydegard, 2012; Szebehely and Meagher, 2018). In these contexts, being defined as frail is a criterion for receiving welfare resources to manage everyday life in old age (Grenier, 2006). Thus, older persons are defined by, and reduced to their needs, which can render their experience and practice-based, relational and emotional resources invisible (Grenier, 2007).

As asserted by various researchers within the field of critical gerontology (Grenier, 2007, 2020; Gilleard and Higgs, 2011; Pickard, 2014; Tomkow, 2020), the normative framework associated with frailty conjures images of frailty as a conceptual antonym to healthy or active ageing, promoted in ageing politics and policy. Healthy or active ageing is associated with independence, autonomy, responsibility and an active lifestyle. By definition, frailty can be seen as a failure to fulfil this ideology (Grenier, 2007; Gilleard and Higgs, 2011; Grenier et al., 2017). In this sense, the concept of frailty serves as a tool to separate the successful agers from the unsuccessful, which also mirrors the separation between the third and the fourth age (Gilleard and Higgs, 2011). The objectifying nature of this classification, or 'frailing', has been highlighted by Higgs and Gilleard (2014), who illuminate how the term frail functions as an othering of old age and experiences of vulnerability. Further, the social construction of frailty encompasses a state of passivity that serves as a focus of others' actions (Gilleard and Higgs, 2010). In light of this definition, older persons resist being defined as frail (Grenier and Hanley, 2007; Warmoth et al., 2016), which might lead to them being denied the health and social care services that they need to manage their everyday life. Moreover, when eligibility for societal resources equals the definition of a failure to fulfil the responsibility to age successfully, there is risk of further stigmatisation of persons in need of such services (Grenier, 2007).

Frailty is generally used as synonymous with vulnerability (Sarvimäki and Stenbock-Hult, 2016). Following the argumentation by Gilleard and Higgs (2010), we understand frailty as a label and categorisation, while vulnerability can be seen as an integrated part of humanity associated with exposure to harmful influence but also with emotional and relational resources (Heidegger, [1962] 2010; Kristensson Uggla, 2014; Sarvimäki and Stenbock-Hult, 2016). As with Butler et al. (2016), we argue that vulnerability is exposed throughout life in situations where social infrastructures are increasingly dismantled and fail to address needs and capabilities, or to tailor services accordingly. As such, vulnerability is not inherent in the individual but emerges through social relationships. Further, vulnerability is a source for setting agentic resources in motion and a condition for reciprocity and solidarity (Butler et al., 2016). Following this reasoning, we argue for adopting a dialectical understanding towards vulnerability, which makes visible how capabilities are enacted when older people framed as 'frail' navigate everyday life in order to exercise democracy in a normative context.

\section{Possibilities for influence when being 'frailed'}

Global as well as national and local policies for service provision to older persons emphasise that service users should be able to influence the services that they 
receive (National Board of Health and Welfare, 2008; World Health Organization, 2015), which is in line with aiming for democracy on the level of everyday life. However, it is not clear whether real differences are being achieved through the strategies applied to older people 'having a say' about services and policies (Barnes, 2005). Furthermore, such strategies tend not to be adjusted to the actual service users, i.e. people who do not manage everyday life independently, which is reflected in that 'fourth agers' are rarely included in projects with a participatory agenda (Ray, 2007; Baur et al., 2013; Bindels et al., 2014; Backhouse et al., 2016).

Mirroring a neoliberal society in general, influence and participation for older persons in health and social care are often framed through the lens of consumerism, which leaves a great part of the responsibility for the health and social care on the older person and their kin (Carey, 2019). In the Nordic countries, as well as in other countries with publicly funded welfare systems, this coincides with the shift from generalist welfare system towards a system where resources are targeted to the individuals with the highest needs (Szebehely and Trydegard, 2012; Szebehely and Meagher, 2018), which in the context of old age means people defined as frail (Grenier, 2007; Tomkow, 2020). From this follows that people are defined as lacking health, independence, autonomy and an active lifestyle, and at the same time expected to act as agentic consumers (Meinow et al., 2011). In line with a consumerist ideology, influence and participation are often presented as the possibility to choose between alternatives, i.e. with which service provider to establish a contract. However, the choice of service provider too often offers few possibilities to influence crucial aspects such as how, when and with whom to perform everyday activities. Moreover, it does not recognise older persons' efforts and resources to act upon their everyday situation (Wray, 2004; Grenier, 2006; Johansson et al., 2009). It is documented that the logics behind the idea of informed decision-making and agency as means for influence has difficulties in matching the unpredictable and situated everyday life of older persons living with multiple health conditions that fluctuate with, for example, symptoms of medical conditions, mood and social relationships, as the situation changes over the day or between days (Johansson et al., 2009; Harnett, 2010; Fjaer and Vabo, 2013; Mondaca et al., 2019). Research has shown that the main concern for older persons with high support needs is to get through the day and maintain some agency, sense of self, self-worth and belonging to a social community, while autonomy and independence is seen as a rather theoretical aspiration (Gilleard and Higgs, 2010; Mondaca, 2018).

The above highlights that present policies and practices are not adequate to support influence in everyday life for older people who need support to manage everyday life, i.e. people who are labelled as frail. Frailty and vulnerability in old age has been widely discussed in the field of critical gerontology (Grenier, 2007, 2020; Gilleard and Higgs, 2011; Pickard, 2014; Tomkow, 2020). Still there is little research that illuminates how the labelling practices of frailty and the non-recognition of vulnerability functions within the everyday life of older people in relation to service provision.

\section{Swedish context}

Eldercare in Sweden is governed by the Social Service Act which stipulates that eldercare shall promote dignity and wellbeing for older people (Sveriges Riksdag, 2001). Eldercare is mainly the responsibility of the municipalities and financed 
by taxes (Swedish Institute, 2021). In practical terms, eldercare in Sweden includes home help, home modifications, transport services, and access to day care centres and nursing homes. In this context, needs-led assessments have been implemented throughout, which implies that the support is specified in great detail based on professional assessments of individual needs. This gives very little space for the older persons and/or the hands-on service provider to negotiate the form and content of the support in relationship to preferences and needs as emerging in everyday situations. This assessment-based prescription of services easily infuses everyday life with a top-down structured tone.

\section{Everyday life challenges when health and social care services are part of everyday life}

In the following, we present examples of everyday challenges, illustrated by the cases of Anders, Sophia and Gunnel. The examples are drawn from different ethnographic studies with older persons in their home environment in a Swedish context, in which the authors have been involved. The examples are chosen as they represent typical situations where democracy in everyday life situations is at stake.

\section{Anders}

Anders is a 66-year-old man who lives alone in an apartment in a suburban area in Stockholm. Since his stroke about a year earlier, he has difficulties with mobility, which makes it difficult for him to transfer in and out of the bathtub to shower. He has access to home help services to support him to shower. However, the home help is scheduled every Thursday at 10 o'clock. Anders has always been up early in the morning, and he still likes to shower directly after a quick cup of coffee in the early morning, saying: 'showering, that's something you do in the morning'. Moreover, due to the consequences of the stroke, Anders' level of energy varies from day to day, and he does not always have the energy to shower on Thursdays as scheduled. Rather than forcing his habits and resources into the schedule of the home help, Anders prefers to struggle to manage showering on his own. He has developed a method to move his legs into the bathtub, using the washing machine as support. Still, he finds this method very exhausting, time consuming and unsafe because he is afraid that he will fall, which actually has happened. For Anders, vulnerability emerges in the conundrum of needing assistance with showering in a safe manner in addition to wanting to take a shower in the morning, and not being able to receive this assistance adapted for his wishes and daily routine. He brings resources to the situation in the form of creativity, physical and practical efforts. However, these resources are enacted in isolation and gain no response from the service-providing institution. Consequently, the possibility to exercise democracy in everyday life as a collaborative practice that involve Anders and the staff is lost, resulting in an unsafe and complicated situation for Anders.

\section{Sophia}

Sophia, a woman aged 82, experiences challenges emerging in the gap between how she wants to structure her day and what is possible based on the organisation of 
services. Sophia lives in an apartment in the city centre of Stockholm. She has lived there for many years, and she feels very comfortable in the local neighbourhood. Due to pain in her back and hip and difficulties with balance, it is difficult for Sophia to walk without a walker and to carry things or to open heavy doors. She is dependent on various services to manage everyday life, including home help and transport services, and she finds it difficult to have immediate influence in emerging situations given the service organisation and routines. To create possibilities to influence when and how to do what she wants and needs to do, and to participate in valued activities, she puts a lot of effort into co-ordinating the different services she needs in the context of her everyday life. Sophia cannot manage to open the entrance door to the building in which she lives. She has applied for an automatic door opener, but the landlord has refused this. Since transport services do not include helping the customer to and from the taxi, Sophia has to co-ordinate the home help with transport services each time she has an errand outside the home, to help her get in and out of the building. For example, on one occasion she was to attend her friend's funeral. She wanted to bring flowers to the funeral. To make this possible she paid to have the flowers delivered to her home and co-ordinated the delivery with her transport services. Additionally, she co-ordinated the time for the home help with this event. Being well aware of the tight schedules and lack of flexibility that directed the work for the home help, she arranged this event one week in advance. Sophia was very frustrated that she had to make this complicated arrangement instead of being able to 'just roll down the road to the flower shop with the walker' and take the transport service from there, which would have been possible with an automatic door opener. This example illustrates how democracy in Sophia's everyday life situation is threatened by the rigid and unco-ordinated services provided. Further, the rigidity provides limited possibilities for joint action among the service provider and Sophia in order to co-ordinate in a way in which Sophia can realise capabilities in her everyday life.

\section{Gunnel}

The third illustration takes place in a nursing home context. Gunnel is excited to visit the nearest forest with a small group of residents as part of an afternoon autumn trip. She is 85 years old, uses a wheelchair and has multiple chronic conditions. She is aware that the trip to the forest includes some time for coffee and conversation, and that she will be away for about an hour. She wants to use the toilet before departing, to prevent 'an accident'. The nurse assistants were meanwhile helping three other residents. They denied Gunnel's wish to use the toilet because it would take time to complete the whole procedure. Gunnel needed maximal assistance when toileting, and there was a shortage of staff available to respond to her demand at that moment. After some discussion, the residents embarked for the forest, so that they would not need to wait given that they were already dressed for the outdoor event. The staff communicated to Gunnel that someone would help her with her toilet visit, but she would not be part of the group going out this time. Gunnel's sadness, anger and frustration was visible, and she said: 'you never know in this place when such a chance [to go out of to the forest] will come again'. For Gunnel, her precaution and integrity led to a negative outcome for 
her in the short term, and conditions to exercise agency were not met sufficiently to create an empowering situation in her own everyday life. The insufficient staffing, limited co-ordination between staff and inflexible routines can be seen as hindering Gunnel in exercising democracy in this particular situation. Outdoor activities are a great challenge to organise and achieve at nursing homes, which added to the frustration for Gunnel who understood that the next opportunity was not likely to be in the near future.

In the above examples, older persons put a lot of effort into influencing their everyday situations in the form of how and when to be engaged in everyday activities, or to 'make it through the day' (Gilleard and Higgs, 2010; Johansson et al., 2009), while they at the same time find themselves in a situation where they are objects of others' actions and decisions. Although resources are available (such as home care for Anders, transport for Sophia, a planned outing for Gunnel), they are not co-ordinated with the older persons' own efforts to transform these resources to something personally relevant. There is a potential of setting capabilities in motion that are not recognised (or overruled) due to rigid structures in the organisation of care, and a failure to address the resources held by older persons defined as frail. The examples illustrate the simultaneous existence of vulnerability and resources through creativity (Sarvimäki and Stenbock-Hult, 2016) as Sophia, Anders and Gunnel use their creative, emotional, practical and social resources to integrate activities in a manner that address their needs and capabilities, and influence the situations in the direction towards how and when to be engaged in everyday activities. In this way, the examples challenge the picture of passivity associated with frailty (Gilleard and Higgs, 2010), and at the same time illustrate how the organisation of services fails to recognise and meet these creative efforts in a reciprocal way. The actions built upon these resources did to some extent result in influence on how and when to perform valued everyday activities. Still this influence is accomplished, through strained physical efforts, a sense of insecurity and complicated planning, in a context that offers limited co-ordinated resources (Johansson et al., 2009), which render vulnerability exposed, as social infrastructures are increasingly dismantled and fail to address needs and capabilities, or to tailor services accordingly (Butler et al., 2016).

Further, the examples illuminate how the targeting approach of welfare resources results in fragmentary services and very little space for the older person and the hands-on service provider to negotiate and act upon the form and content of the support in relation to preferences, needs and relationships emerging in everyday situations. This puts older persons as well as staff in a vulnerable position as staff face the exhausting dilemma of not being able to meet the needs of the older persons in line with their professional ethics nor being able to meet the employers' demands (Vik and Eide, 2012). Moreover, this organisation of services assumes everyday life in a rigid way, leaving no space for contingencies and therefore threatening democracy in everyday situations. The examples are drawn from a Swedish context. However, on a socio-political level there are elements that can be recognised in an international context. Even though the organisation of health and social care for older persons varies between nations, older person's efforts to transform health and social care services into something personally relevant in the context of neoliberalism can be recognised in many European countries and around the world. 


\section{Recognising vulnerability and resources - a relational conceptualisation of} democracy

The illustrations suggest that an understanding of vulnerability that includes the ability to set resources in motion and generate resistance to practices that inhibit influence is needed to enhance democracy (Butler et al., 2016) in situations where health and social care is an integrated part of everyday life. The argument here is not that everyone should get 'what they want', rather that there is a need to move beyond autonomy and self-determinism towards a perspective that recognises the situated, reciprocal and emergent character of influence (Mondaca et al., 2019). Democracy is emphasised as a resource to potentially shift the objectifying practice of 'frailing' towards situated and contextual perspectives that recognise and respond to how people like Anders, Sophia and Gunnel enact possibilities of active citizenship and democracy in vulnerable situations (Grenier, 2004; Wray, 2004; Grenier and Hanley, 2007; Butler et al., 2016). With this perspective, vulnerability is palpable secondary to the failure of social infrastructure (Butler et al., 2016) rather than as individual deviation from normality (Grenier, 2007). This aligns with the argument that resources are to be seen as relational, rather than as individual features (Nolan et al., 2004; Katz and Alegría, 2009; Baur et al., 2013; Bindels et al., 2014; Mondaca et al., 2019).

Various tools and approaches have been suggested to meet the policies that emphasise participation and influence for older persons in relation to service provision, including, for example, person-centred care and participatory research and practice approaches (Bourke, 2009; Baur et al., 2013; Backhouse et al., 2016). Such approaches strive to define and articulate rights, needs and preferences, collective as well as individual. Being important and promising attempts, such approaches tend to dismiss the situated, reciprocal and emergent character of influence and everyday life (Cutchin, 2003; Frank, 2005; Johansson et al., 2009; Mondaca, 2018). An understanding of democracy as relational instead of as individual rights, as proposed in this article, includes older people's resources and needs, and emphasises alternative modes of engagement of service providers when entering the everyday life of older people. Yet, there is little knowledge and experience to draw upon when aiming to enable and support influence and democracy in this sense.

\section{Concluding remarks}

We have argued that limiting conceptualisation and operationalisation of democracy to the articulation and execution of autonomy and rights fails to recognise the situated nature of human capabilities. Drawing on discussions regarding frailty within critical gerontology, our discussion of the presented cases highlights how the practice of 'frailing' prevents people living with multiple chronic conditions from realising capabilities inherent to central values of democracy and citizenship in everyday life, in situations where health and social care services are part of everyday life.

This argumentation points to health and social care services that provide and build social infrastructures needing to recognise the potential concurrency of interdependency, vulnerability and agency within older persons' local everyday practices. Such a shift is pivotal to address capabilities and enable concrete expression of democracy in everyday situations (Sen, 2010; Nussbaum, 2011). Further, it requires 
a shift in power relations to provide possibilities for health and social care staff and older persons to negotiate the form and content of the support in relationship to preferences and needs as emerging in everyday situations, which at present is inhibited by rigidity and instrumentalism inherent in cost-effectiveness and neoliberalism.

Overall, we suggest that conceptual and methodological shifts in research, as well as policy and practice, are needed to bring democratic processes forward through the relational and situated aspects of resources, agency and influence. However, such a shift is not compatible with a neoliberalism that informs many parts of an international context where people are defined through their potential as consumers rather than through their potential and rights to exercise democracy in their everyday as well as political life. Consequently, there is a need for a radical shift in the ideological underpinnings of the organisation of health and social care services for older people.

\section{References}

Backhouse T, Kenkmann A, Lane K, Penhale B, Poland F and Killett A (2016) Older care-home residents as collaborators or advisors in research: a systematic review. Age and Ageing 45, 337-345.

Barnes M (2005) The same old process? Older people, participation and deliberation. Ageing \& Society 25, 245-259.

Baur VE, Abma TA, Boelsma F and Woelders S (2013) Pioneering partnerships: resident involvement from multiple perspectives. Journal of Aging Studies 27, 358-367.

Bindels J, Baur V, Cox K, Heijing S and Abma T (2014) Older people as co-researchers: a collaborative journey. Ageing \& Society 34, 951-973.

Bourke L (2009) Reflections on doing participatory research in health: participation, method and power. International Journal of Social Researh Methodology Bourke L, 457-474.

Butler J, Gambetti Z and Sabsay L (2016) Vulnerability in Resistance. Durham, NC: Duke University Press.

Carey M (2019) Some limits and political implications of participation within health and social care for older adults. Ageing \& Society 39, 1691-1708.

Cutchin MP (2003) The process of mediated aging-in-place: a theoretically and empirically based model. Social Science and Medicine 57, 1077-1090.

Eales J and Keating N (2001) Seniors' experiences of client-centred residential care. Ageing \& Society 21, 279-296.

Fjaer EG and Vabo M (2013) Shaping social situations: a hidden aspect of care work in nursing homes. Journal of Aging Studies 27, 419-427.

Frank AW (2005) What is dialogical research, and why should we do it? Qualitative Health Research 15 , 964-974.

Gilleard C and Higgs P (2010) Aging without agency: theorizing the fourth age. Aging and Mental Health 14, 121-128.

Gilleard C and Higgs P (2011) Frailty, disability and old age: a re-appraisal. Health 15, 475-490.

Grenier A (2006) The distinction between being and feeling frail: exploring emotional experiences in health and social care. Journal of Social Work Practice 20, 299-313.

Grenier A (2007) Constructions of frailty in the English language, care practice and the lived experience. Ageing \& Society 27, 425-445.

Grenier A (2020) The conspicuous absence of the social, emotional and political aspects of frailty: the example of the White Book on Frailty. Ageing \& Society 40, 2338-2354.

Grenier A and Hanley J (2007) Older women and 'frailty'-aged, gendered and embodied resistance. Current Sociology 55, 211-228.

Grenier A, Lloyd L and Philipson C (2017) Precarity in late life: rethinking dementia as a 'frailed' old age. Sociology of Health and Illness 39, 318-330.

Harnett T (2010) Seeking exemptions from nursing home routines: residents' everyday influence attempts and institutional order. Journal of Aging Studies 24, 292-301. 
Heidegger M ([1962] 2010) Being and Time. Albany, NY: State University of New York Press.

Heikkinen RL (2004) The experience of ageing and advanced old age: a ten-year follow-up. Ageing \& Society 24, 567-582.

Higgs P and Gilleard C (2014) Frailty, abjection and the 'othering' of the fourth age. Health Sociology Review 23, 10-19.

Johansson K, Josephsson S and Lilja M (2009) Creating possibilities for action in the presence of environmental barriers in the process of 'ageing in place'. Ageing \& Society 29, 49-70.

Katz AM and Alegría M (2009) The clinical encounter as local moral worlds: shifts of assumptions and transformation in relational context. Social Science and Medicine 68, 1238-1246.

Kristensson Uggla B (2014) Personfilosofi - filosofiska utgångspunkter för personcentrering inom hälsaoch sjukvård. In Ekman I (ed). Personcentrering $i$ hälso- och sjukvård: från filosofi till praktik. Uppsala, Sweden: Liber, pp. 58-105.

Larsson Å (2009) Everyday Life Among the Oldest Old - Descriptions of Doings and Possessions and Use of Technology. Linköping, Sweden: Linköping University.

Meinow B, Parker MG and Thorslund M (2011) Consumers of eldercare in Sweden: the semblance of choice. Social Science and Medicine 73, 1285-1289.

Mondaca M (2018) It's My Party. Opportunities for Older Adults to Influence Everyday Activities in a Nursing Home Setting. Stockholm: NVS, Division of Occupational Therapy, Karolinska Institutet.

Mondaca M, Josephsson S, Borell L, Katz A and Rosenberg L (2019) Altering the boundaries of everyday life in a nursing home context. Scandinavian Journal of Occupational Therapy 26, 441-451.

National Board of Health and Welfare (2008) Brukarinflytande inom äldreomsorgen [User Influence in Elderly Care]. Stockholm: Socialstyrelsen.

Nolan MR, Davies S, Brown J, Keady J and Nolan J (2004) Beyond person-centred care: a new vision for gerontological nursing. Journal of Clinical Nursing 13, 45-53.

Nussbaum M (2011) Creating Capabilities. The Human Development Approach. Cambridge, MA: The Belknap Press of Harvard University Press.

Pickard S (2014) Frail bodies: geriatric medicine and the constitution of the fourth age. Sociology of Health and Illness 36, 549-563.

Ray M (2007) Readdressing the balance? The participation of older people in research. In Bernard M and Scharf T (eds). Critical Perspectives on Ageing Societies. Bristol, UK: Policy Press, pp. 73-87.

Sveriges Riksdag (2001) Socialtjänstlag SFS 2001:453. Available at https://www.riksdagen.se/sv/dokumentlagar/dokument/svensk-forfattningssamling/socialtjanstlag-2001453_sfs-2001-453.

Sarvimäki A and Stenbock-Hult B (2016) The meaning of vulnerability to older persons. Nursing Ethics 23, 372-383.

Sen A (2010) The Idea of Justice. London: Penguin.

Swedish Institute (2021) Elderly Care in Sweden. Available at https://sweden.se/life/society/elderly-care-in-sweden.

Szebehely M and Meagher G (2018) Nordic eldercare - weak universalism becoming weaker? Journal of European Social Policy 28, 294-308.

Szebehely M and Trydegard GB (2012) Home care for older people in Sweden: a universal model in transition. Health and Social Care in the Community 20, 300-309.

Tomkow L (2020) The emergence and utilisation of frailty in the United Kingdom: a contemporary biopolitical practice. Ageing \& Society 40, 695-712.

Vik K and Eide AH (2012) The exhausting dilemmas faced by home-care service providers when enhancing participation among older adults receiving home care. Scandinavian Journal of Caring Sciences 26, 528-536.

Warmoth K, Lang IA, Phoenix C, Abraham C, Andrew MK, Hubbard RE and Tarrant M (2016) 'Thinking you're old and frail': a qualitative study of frailty in older adults. Ageing \& Society 36, 1483-1500.

World Health Organization (2015) Global Strategy and Plan of Action on Ageing and Health. Geneva: World Health Organization.

Wray S (2004) What constitutes agency and empowerment for women in later life? Sociological Review 52, 22-38.

Cite this article: Asaba E, Mondaca M, Josephsson S, Johansson K (2021). Everyday influence - democracy when health and social care are part of everyday life. Ageing \& Society 1-10. https://doi.org/10.1017/ S0144686X21001653 